\title{
Student's Management of Covid-19 Fake News/Miss Information During the Pandemic
}

\author{
Faiswal Kasirye (Ph.D.) \\ Department of Communication, International Islamic University Malaysia \\ *Corresponding author email: Kasirye.faiswal@gmail.com
}

\begin{abstract}
Education activities have embraced difficulties and challenges in managing their students who reside at respective learning institutions since the outbreak of the COVID-19 pandemic. with this age of digital information flow, anyone can share any information related to any issue and in any way they want because of the free access to information that is proving to be inalienable. The main aim of this paper is to find out the strategies that students used in managing COVID-19 miss information during the present Covid crisis. The study uses the situational crisis communication (SCCT) theory to help in guiding the study and explaining the strategies that might have adopted by students in distancing themselves from the fake news regarding the Covid crisis to survive at campus with the right information. A qualitative research approach using the interview as the method with an interview schedule as the tool for data collection was used in this study. Responses were extracted from IIUM students for this study. The findings of the study reveal that students used both university sources and social media to get relevant information related to Covid19. Also, to counter miss information, they would check with the information supplied by the university to counter the fake news that was circulating regarding the Covid crisis. The situational crisis communication theory guided the study well.
\end{abstract}

Keywords: COVID-19 crisis, Situational crisis communication theory, miss information/fake news, strategies 


\section{INTRODUCTION}

The internet has brought a wealth of knowledge and information to the fingertips of those who use it. However, despite its perceived positive uses, the influx of information on it has brought issues such as misinformation, fake news, and fear in the public. As a result, online users have trouble distinguishing between what is true and what is false. Since the outbreak of the novel corona virus, fake news has rampantly emerged as a significant factor that not only affects people as a whole, but also many organizations around the world.

According to WHO (2020), coronavirus is comprised of a large family of viruses that cause illnesses ranging from the common flu to more severe diseases such as the Middle Ease Respiratory syndrome (MERS-CoV) and among others. The novel coronavirus or known as COVID-19 is a new strain that has not been previously identified in humans. All around the world, people have been infected and died in the millions due to the lack of necessities and education on how to prevent the spread of the coronavirus. Health organizations are all attempting to treat patients while gaining a better understanding of the virus and how it rapidly disperses it onto the public.

As anyone might expect, fear, deception, and misinformation have spread widely on social media. Organizations like The World Health Organization, The Centers for Disease Control and Prevention, as well as local organizations such as the Ministry of Health Malaysia along with other public health organizations are at the forefront of providing information to the general public.

Ragavan (2020) believes, that one of the things that help an organization or a brand to navigate important decisions in times of emergency or crisis is a strong organizational culture and a solid sense of brand identity. Prioritizing the needs of a business and its stakeholders is the core of communication tactics and strategies. With that being said, it's vital to be aware of how those needs line up with an organization's brand identity and qualities.

If a company acts against its stated or embodied values by prioritizing profit or publicity at the wrong time, it may be seen as unscrupulous or opportunistic. For this reason, many brands are abstaining from commenting or providing donations such as fundraising or supplies (Ragavan, 2020). It is indispensable to be aware of others and continue to mirror your organization's values. Irrespective of how a brand prefers to communicate, it is fundamental to think on a global scale 
and grasp a comprehensive mindset. After all, the disease does not discriminate. Therefore, this study aims to examine how organizations, in a particular deal and manage fake news using crisis response strategies as a tool during emergencies like the current COVID-19 pandemic in Malaysia, but more specifically at International Islamic University Malaysia (IIUM).

\section{STATEMENT OF THE PROBLEM}

As the famous philosopher Andrew Smith once said, "We fear what we don't understand". This is a common understanding among people nowadays. The notorious COVID-19 corona virus continues to dominate the headlines in today's world, more and more people are now in a state of fear over the corona virus and what it can do to those who have it. The corona virus is very much a public relations issue. Thus, health organizations and institutions must use public relations campaigns to try to mitigate and lessen the fears of the public.

Everyone should prepare themselves when it comes to crises like the COVID-19 pandemic that has so far wretched the entire world that came with lots of information including negative news related to the corona virus pandemic. institutions of higher learning are always hit with such negative information and usually affect the students most of whom stay and or are confined at their respective campuses. This is done to not only protect the wellbeing of students and their belongings at the various center of learning.

Also, the use of social media has drastically increased as people were going into their homes to quarantine. This led to a growth in the usage of the technology world over as it became the main way for people to communicate. Such expansion has also led to an increase in fake news. Shu, Sliva, and Wang (2017) argue, that social media has two sides to the same coin. On one hand, it gives rise to convenience and accessibility while giving rise to an upsurge of low-quality news and misinformation. This makes it difficult for many people to distinguish between real news and fake news. Such has happened to the students at IIUM where many have been hit by an influx of misinformation regarding the COVID-19 Pandemic. the most worrying issue among students is distinguishing between what is a piece of fake news and what is not because they are not sure what constitutes it. This has been proved to be a danger to them for, they end up posting unconfirmed information related to COVID-19 which has resulted into miss leading information regarding the cases of COVID -19 that have happened at the university. 
Hence, this study was conducted at International Islamic University Malaysia (IIUM) due to its heightened attention with regards to coronavirus (COVID-19) as well as the lack of research with the virus concerning how the students are copying up with the many un confirmed reports regarding the cases of the virus in the university. Specifically, this study aims at exploring how IIUM students managed COVID-19 miss information to avoid panic during these crisis times.

\section{Research Objectives and Questions}

The main objective of the study is to examine strategies employed by IIUM students in managing fake news and misinformation regarding the COVID-19 outbreak at the campus.

The specific questions are;

1. What are the strategies employed by students in managing fake news during the outbreak of COVID-19?

2. What challenges did students face as a result of managing fake news and misinformation regarding COVID-19 at campus? and

3. How did the students overcome the challenges they faced in managing fake news and misinformation at Campus during the outbreak of COVID-19?

\section{SIGNIFICANCE OF THE STUDY}

Institutions such as IIUM need to control the spread of fake news miss information through crisis response strategies during the rampant spread of the corona virus. Many organizations usually take steps to minimize fake news and its impacts. In addition, students are also advised to be on alert especially in situations like the present crisis because they depend more on social media for information regarding particular crisis like the pandemic. therefore, this study will provide valuable insights to the students on the strategies that they need to take while encountering miss information and fake news on the internet but especially on social media. Also, once students are well informed on the matter, it is in their interest to ensure that they are capable of protecting themselves from the virus.

The findings of this study will also contribute to a greater body of knowledge in understanding crisis response strategies through the underlying framework of the situational crisis communication theory (SCCT). The theory has been used before in similar studies but not under 
institutions of learning like IIUM as well as managing a crisis like the current pandemic in an institution of learning. As will be highlighted in the literature review, several studies on fake news during crises have generally been carried out in the United States and Europe at large. There is minimal research carried out on this subject of the crisis response strategies during a crisis like COVID-19 particularly in a local institute of higher learning such as IIUM. Therefore, this paper attempts to fill the gaps in research on the crisis response strategies employed by International Islamic University Malaysia (IIUM) students in managing the crisis of misinformation and fake news relating to COVID-19.

The study hopes to contribute to the field of crisis communication and health communication because the students will be able to highlight the problems they faced and the solutions that they used to inform of strategies in managing the crisis at hand which is the pandemic. These findings therefore will guide future students who might face the same crisis on what strategies they might take if they ever come across such crises in their lives.

In addition, universities are now under intense scrutiny from the public and students as information is now readily available for the world to see. Communication and management have taken a new level of importance during this pandemic. Higher learning institutions must now rethink how to manage and treat students as stakeholders, that help them to fight enemies in such crises. Reinventing new ways using crisis response strategies is vital to ensure a healthy relationship between the students and the university. This hopes to shed light on the importance of image presentation that meets both the needs of the students and the university.

The findings from this study will provide useful information for the management of the university in regulating information flow among students and staff to minimize the spread of fake news and miss information during a crisis like the present pandemic.

For practical implications, the findings will also serve as a guiding tool for policy formulation and implementation by the university and the government of Malaysia regarding the management of fake news and miss information especially among students, and also act as a tool to guide the formulation of future policies regarding the penalties for those caught in the act of spreading misinformation to the public. 
The findings from this research will also add significantly to the bulk of existing scholarly knowledge in this domain of fake news and will be eminent among IIUM and its students where little has been done about the management of fake news among students during a crisis.

\section{LITERATURE REVIEW}

\section{Situational Crisis Communication Theory (SCCT)}

Situational Crisis Communication Theory (SCCT) was developed by Coombs in 1995. According to Coombs (2004), to protect the reputation of an organization, the theory provides a framework for use in crisis communications.

In several cases, the SCCT model has been validated and considered applicable in many studies on reputation management of crises and post-crises. According to Thiessen and Ingenhoff (2011), they argue, that progress in handling crisis communication needs to be discussed and conceptualized at various, particular levels of complexity. Where a crisis has been treated badly, organizational integrity and the history of partnerships can be adversely affected.

To relate with the current study, IIUM and the students faced a crisis that threatened the university's reputation during the onset of the pandemic. The crisis began when IIUM decided to close the university for 10 days while other universities were still open. During this time, there were a lot of rumors and fake news spreading by people because they thought IIUM had been closed because of the current pandemic.

This theory proposed several types of crises, there are a few clusters of crises put forward by Coombs, of which one of them is the victim crisis. This type of crisis as explained by Coombs happens in an organization while it may not have anything to do with the crisis. A victim crisis happens when rumors are spreading by people about the organization. Thus, IIUM can be classified as the victim because of the rumors and fake news that people were spreading as a result of the temporary closure of the university.

There are also a few strategies that are mentioned by Coombs in this theory of which one of which is the deny strategy. Organizations can use this strategy by claiming that there is no crisis. This strategy can be used for victim crisis when an organization faces rumors or accusations that are not true. For instance, IIUM used this strategy by coming out with a statement that clarified and 
quashed all the rumors that were spreading among students and the general public concerning a COVID-19 case at the university. Hence, the theory is very appropriate to guide the current study. Therefore, based on the above literature on the SCCT, the theory is preferred to guide the current study because it related to solving crises in crises like the present pandemic and finding out the appropriate strategies that students could take to overcome the spread and effect of COVID-19 miss information and fake news on them.

\section{COVID-19 in Malaysia}

In December 2019, the World Health Organization announced a novel coronavirus (COVID-19) which was caused by SARS-CoV-2 as a pandemic. This virus started spreading from Wuhan, China as an epidemic before other countries got affected and became a global pandemic (Lipstichh $\&$ Swerdlow, 2020). Within just two months, driven by a huge aviation industry, it had become a pandemic (World Health Organization, 2020).

The first cases in Malaysia were detected on 25th January 2020. Investigations found out, that the patient had close contact with people who were infected in Singapore (Singhal, 2020; World Health Organization, 2020). The ministry of health $(\mathrm{MOH})$ Malaysia was quick to create standard guidelines for COVID-19 management. In each state of Malaysia, there were 34 hospitals and screening centers were officially put in place (Ministry of Health, 2020).

On 4th February 2020, there was a 41-year old man who had just returned from Singapore was the first Malaysian confirmed with COVID-19. He started developing a cough and a fever and was quarantined at Hospital Sungai Buloh, Selangor (Borneo Post, 2020). However, on the same day, a Chinese national girl had recovered and she was allowed to return to China (Bernama, 2020). Since the outbreak, she was the first patient in Malaysia who recovered from COVID-19.

However, by 5th April 2020, Boo (2020) stated that there were 3662 cases in Malaysia and 61 recorded deaths. According to the Ministry of Health (2020), the Malaysian Government took timely action in the area of public health to avoid an unprecedented increase in cases by continuously testing and screening individuals at high risks, isolate patients and trace all the close contacts and quarantine them to avoid a secondary spread. 
Such acts seem appropriate before a wide cluster of cases that took place after a massive Tabligh meeting in late February that involved more than 10,000 people (Ministry of Health, 2020). The incident had already changed the shape of the Malaysian epidemic curve (Ministry of Health, 2020). Ministry of Health also mentioned, that there was an urgency in managing the outbreaks to prevent the healthcare system from collapsing which prompted the government to implement stricter action (Surico \& Galeotti, 2020). Then, on 16 March 2020, the Prime Minister of Malaysia announced the Movement Control Order (MCO) which was a limited lock-down.

The first MCO (MCO1) began on March 18 until March 3, 2020. McKibbin and Fernando (2020) say, that MCO2 continued from 1st April until 14th April 2020. All schools, universities, religious places including mosques and churches were closed during the MCO. Not only that, but the general public was also not allowed to cross to other states albeit with stronger reasons. However, some family members were allowed to go out and buy groceries with several conditions of moving within a $10 \mathrm{~km}$ radius but also wearing a mask all the time. During that time, both the army and police worked together to make sure that the public follows the standard operating procedures (SOPs) during the MCO.

AT IIUM, students started getting rumors regarding positive cases at the university right after the university was closed during a 10-day closure, something that sparked off a lot of miss information on social media to the extent of even reaching the parents of some students. this tainted the image of the university as the culprits were students but they were not spreading the right information because they had not asked for the relevant information from the relevant authorities. This affected many students both who were staying at campus ", mostly international” as well as those who had gone back to their home areas. The university tried to do damage control and see how to rectify the situation but fake news had already circulated on social media and the students started getting a lot of panic and some isolations whenever they would go out of the university to associate with the people outside the campus because of the miss information that had hit the social media waves.

\section{Infodemic}

Infodemic is a word with a combination of information and epidemic. It occurs when health emergencies emerge. According to Hu, Yang, Li, and Zhang (2020), the term was coined in 2003 by David J. Rothkopf during the SARS-CoV epidemic that hit the world then. It describes an informational epidemic that is combined with misinformation, disinformation, false news, rumors, 
and conspiracies. While in 2004, Gunther Eyesenbach invented the term infodemiology to mean "a novel transdisciplinary branch to unravel the complex propagation patterns of the infodemic, along with the term "Infoveillance" which translates into a type of syndromic surveillance that utilizes online contents" (Hu, Yang, Li \& Zhang, 2020, p. 15).

While fighting the infodemic, different campaigns are being held by WHO and other different practitioners. The campaigns are divided into three categories. The first campaign is an infodemic campaign that was endorsed by WHO and partnered with internet giants over the world. The second campaign is a disinfodemic campaign whereby every organization is responsible for holding the campaign that is being led by UNESCO.

On February 2, 2020, the World Health Organization (WHO) defined infodemic as an excessive amount of information available on social media that is both accurate and some are not accurate, hence when people need information that is trustworthy and reliable, it is hard for them to find it. Infodemic became a very serious issue when the COVID-19 pandemic occurred. It is a situation where there is a lot of information related to COVID-19 that is reliable and unreliable circulating online. According to WHO (2020), its Director-General, Tedros Adhanom Ghebreyesus said, that they are not just fighting an epidemic but also an infodemic.

Furthermore, infodemic is seen as a serious issue for public health because people require advice or guidance to take action for them to protect themselves and others around them and help diminish the impact of the disease. Information that is related to the COVID-19 pandemic includes unproven medical methods to cure the virus such as use salty water to rinse the mouth, eating oregano, and drinking bleach. Not just that, there are also myths regarding this virus whereby consuming 'bat soup' are the cause of infection and conspiracies, the US set up the virus and spread it to the world (Chakravorti, 2020, as cited in Pulido, Villarejo-Carballido, Redondo-Sama \& Gómez, 2020).

Lastly, is the misinformation campaign that is supported by other practitioners ( $\mathrm{Hu}, \mathrm{Yang}, \mathrm{Li} \&$ Zhang, 2020). To find out more about infodemic during the COVID-19 pandemic, there is research conducted by Pulido, Villarejo-Carballido, Redondo-Sama \& Gómez (2020) on false and true information shared via Twitter which may help in highlighting more of this. The study indicated, that evidence-based information related to COVID-19 is being shared more than misinformation. To be exact, people tend to tweet but not retweeted false information. 
In the end, it can be concluded that infodemic has been an issue since a decade ago when there was a situation related to a public health emergency. This is when people have access to social media, they tend to post and share false or true information without needing someone to filter the information.

\section{Miss Information and Fake News}

The word fake news or normally known as a hoax has been known since the earliest days of printing during the $16^{\text {th }}$ and $17^{\text {th }}$ centuries where printing companies printed out massive pamphlets or news books that contained excessive news such as a monstrous beast or unusual occurrences that do not have any solid evidence (Standage, 2017). The term fake news has been conceptualized differently by many scholars throughout the years and the meaning of it evolving from time to time. According to Allcott and Gentzkow (2017), they define fake news is deliberately and verifiably false news articles that could mislead readers. Uberti (as cited in Nelson \& Taneja, 2018, p. 2) said, "the term more commonly refers to false or misleading information made to look like a fact-based news story to influence public opinion or cull digital advertising dollars".

Miss information can also be defined as information that is fabricated. In other words, the news or information mimics the original media content but not in established organizational process or intent and are circulated with an intention of miss informing the public. Moreover, non-established organizations or fake news outlets do not have credible people inside the organizations hence, they lack editorial norms and processes in ensuring accuracy and credibility of the news or information. Not just that, fake news also leads to information disorders such as misinformation which is false information, and disinformation which is the intention to purposely spread false information to deceive people (David et al., 2018).

Fake news has recently become more widespread in the presence of new media. Irresponsible people tend to use social network platforms such as Facebook and Twitter to spread and share invalid information that can lead to serious problems. According to Queenie Wong (2019), adults in the United States prefer to get their news through social media and $60 \%$ of them said, that they had shared false information. However, as for adults that chose conventional media as their source of information or news, $51 \%$ of them said they had shared fake news. 
In Malaysia, based on an article on The Asean Post by Liyana Hasnan (2019), a study by IPSOS in 2018 on 'Malaysians' susceptibility towards fake news showed, that 50 percent of Malaysians think that, some of the fake news might be true, even though 74 percent of them acknowledged that they can detect the fake news by themselves. Furthermore, according to Cyber Security Malaysia's (CSM) statistics, from January to April 2019, a total of 2,977 incidents were reported and cyber fraud was the highest number of incidents with 1,963 cases among which include fake news dissemination, impersonation, and offering non-existent services.

\section{COVID-19 and Miss Information/Fake News}

There is a lot of misinformation regarding many things that are shared through mass media or new media. This can be seen in today's world whereby there is various news that is published during this pandemic. This new virus is believed to have originated from Wuhan, China in December 2019 and has so far affected millions of people to countless deaths the world over. This virus is one of the 'deadliest' viruses because there is still no cure that can for it and its recovery only depends on the patient's immune system (The Guardian, 2020). The outbreak of COVID-19 makes some irresponsible people spread fake news about it. This spreading of information leads to misinformation and causes many serious problems to everybody including the government of a country. This fake news regarding COVID-19 not only been spreading across other parts of the world but also in Malaysia.

Jason (2020) deduced that majority of coronavirus information comes from miss information and fake news websites. This can be seen whereby there are more than 106 websites in the United States and Europe that spread fake news about COVID-19 to the entire world. Not just that, official sources that disseminate news about COVID-19 such as the Centers for Disease Control (CDC) and the World Health Organization (WHO) get a small amount of social engagement concerning COVID-19. This is where for the past year since its outbreak, posts from CDC and WHO websites have received many engagements or likes, shares, and comments on social media regarding Covid19, and several other fake news websites have published COVID-19 misinformation with the same likes, shares, and comments.

In Malaysia, several cases have been highlighted towards this issue as spreading fake news irresponsibly and most of them got charged because of irresponsibility behavior. For example, a government retiree from Sabah State Railway Department was one of the people that were caught 
spreading COVID-19 miss information. The culprit was fined RM5,000 resulting from a WhatsApp message he sent regarding a prisoner in Sandakan Prison that had died because of COVID-19 (The Star, 2020). In addition, according to the Malaysian Communications and Multimedia Commission (MCMC), four individuals were detained after spreading fake news during the epidemic of COVID-19. This is where a part-time tutor aged 49 was detained in Alor Setar, Kedah, and reportedly uploading fake news about COVID-19 on Facebook on January 25, 2020. On the other hand, there was also a 24-year-old student who was detained in Kuantan, Pahang for allegedly sharing false information about COVID-19 on Twitter on January 27, 2020 (Ang, 2020).

Also, even though there is news regarding people that have been detained after spreading and sharing fake news and false information regarding COVID-19, until today, false information about COVID-19 is still being shared by people through social platforms. The Ministry of Health Malaysia $(\mathrm{MoH})$ has exposed all the latest fake news regarding COVID-19 through their social media pages. They screenshot the fake messages that have been circulating through WhatsApp and post them on their social media platforms to try and inform others to not believe and spread unverified information as was documented by Ang (2020).

Fake news related to COVID-19 during the onset of the outbreak was seen to be spreading at International Islamic University Malaysia (IIUM). The university tried its best to encounter all the misinformation that was circulating about the university having COVID-19 cases as a result of a 10-day closure that was announced by the university management to try and access the severity of the issue inside and outside the university. For example, there was a post regarding new students from China who were positive of the virus and that they were allowed to enter the university. This prompted the administration to encounter the post with accurate information about the incident that the false post was referring to. The university henceforth gave clear guidelines to students on what they are supposed to do in regards to such incidents and warned them to not indulge themselves in posting unverified I formation that may malign the image of the university when they can just ask them for clarification before posting such.

Generally, from the discussion above, it can be concluded that the issue of fake news, false information, misinformation, and disinformation will never be solved and will become a debatable issue from time to time especially in this era of digital media where everyone who has a gadget 
can post anything as they wish for, they have absolute freedom of speech and information. People have the access to the internet. Thus, some of them take that opportunity for granted, and they resort to sharing and spreading fake news via social media such as Facebook, Twitter, and Instagram. From there, many problems arise and affect many people and organizations at large.

\section{Strategies for Managing Miss Information/Fake News}

Platforms on social media are not favored in public relations since people sometimes face uphill challenges to show their credibility in communication (Sprout Social, 2018). Wynne (2016) argues, that fake news is the biggest challenge facing strategists all over the globe.

Communication strategists should act quickly by monitoring social media, choose the right spokesperson, develop messages and prepare statements. This can help in being prepared if the rumors or fake news begins to spread (Haber, 2017). Also, communication strategies can be used by anyone students inclusive to counteract fake news or counterfeit news and different kinds of fake news such as online fake news for achieving different communication goals.

Senger (2005) deduces, that there are differences between the strategy and the stratagem concept. Strategy is a long-term preparation to achieve certain objectives, different from tactics which are short-term plans. However, stratagem is a 'trickery' or a 'cunning' neutral word, a trickery that is free from deception. Trickery is an uncommon, artful, cunning approach to problem-solving but sometimes needs the use of deception. According to Farte and Obada (2018), public strategists can be as well fake news sources and thus use various types of fake news.

The scholars also considering that communication strategists may use a group of active strategies to neutralize the bad impacts of fake online news. There are six strategies mention by Smith (2002) which pre-emptive action, offensive response strategies, defensive response strategies, diversionary response strategies, vocal commiseration strategies, rectifying behavior strategies, and strategic inaction. It clearly states that communication strategies in crises are among the most effective strategies to handle miss information and fake news. Farte and Obada (2018) argue in their study, that the typologies of communication strategies by Timothy Coombs (1997) and William Benoit (1997) can be proposed in such crisis circumstances to manage fake news.

\section{RESEARCH METHODOLOGY}




\section{Research design and method}

The study employed a qualitative design using the interview as the method to get an in-depth understanding of the strategies applied by IIUM students in managing fake news and misinformation regarding COVID-19 at the campus.

A qualitative interview allows an inductive approach by generating frames from selected codes as extracted from the interview transcript (Kasirye et al., 2020). It identifies underlying themes in the transcripts examined and supports them with brief quotations from the comments and text analyzed, marking the inductive approach (Bryman, 2016). The study will be an exploration of the PR strategies that were employed by IIUM in managing fake news during the outbreak of the COVID-19 at IIUM.

The inductive process of defining frames by identifying themes and codes (Hsieh \& Shannon, 2005 ) is suggested for this study. The inductive process was done due to a lack of predetermined frames in previous studies of similar nature. The lack of a structured process for identifying themes usually associated with such studies (Bryman, 2012) made it easy for the study to adopt the coding and thematizing technique for Braun and Clarke (2006). The interview here comprised of thematizing, coding, and the categorization of data into the different frames. Therefore, in this study, the main interviews with the IIUM strategists on its different media platforms were primarily examined and generated enough data to answer the research questions on the study.

\section{Sampling}

The study adopted a purposive sampling to examine strategies employed by students in managing miss information and fake news relating to COVID-19. For purposes of clarity and in-depth analysis of the strategies, interviews were carried out with 15 students who had been affected or encountered fake news in their social media platforms while carrying out their studies at IIUM. These were chosen to base on their knowledge on the subject of fake news and whether they have had an incident regarding the issue, and how they have tried to address the issue to stop miss information o COVID-19.

\section{Data collection}

The interviews were digitally recorded from IIUM students and thematically analyzed to explore the different strategies employed by students in fighting miss information and fake news on their 
social media platforms. Selective analyses were carried out on several issues from the interview that is relevant to the research objectives and questions. "Valid analysis is hugely aided by data displays that are focused enough to permit viewing of a full data set in one location and are systematically arranged to answer the research questions at hand." (Huberman \& Miles, 1994).

Furthermore, Duranti (2006) explains, "A more valuable analysis is a more selective one, as irrelevant information makes the outcome difficult to read and might make the research purpose incomprehensible" (Duranti 2006 p.304).

Thematic analysis in this study was preferred from Braun and Clarke (2006) who described the phases of thematic analysis of transcripts as familiarizing yourself with your data, creating initial codes, looking for themes, reviewing themes as well as defining and naming them.

\section{Validity and reliability}

For the present study, the extracted data in form of verbatim transcripts were given to experts who specialize in English language and qualitative studies, for purposes of them being examined for accuracy by comparing and reviewing codes and themes to qualify the meanings of the data. Due to the exploratory nature of this study, the study used open variables to determine the content of the interviews and their theme framework.

To ensure the trustworthiness of qualitative research data, researchers are advised to undertake the audit-trail procedure (Carcary, 2009). The trial is carried out by way of providing the relevant documentation and or verbatim transcripts to professional persons such as academicians and others who are experienced in qualitative research studies to establish the meaning of the data (Lincoln \& Guba, 1985; Anney, 2014).

\section{The Interview}

The study employed semi-standardized interviews to allow interviewees room for flexibility to answer as many questions as possible in any direction. Semi standardized interviews offer a more flexible approach to the interview processes. While they may use an interview schedule for

predetermined topics, they allow for unanticipated responses and issues to emerge through the use 
of open-ended questioning (Tod, 2006). Berg (2009) adds, that the wording of questions here has to be flexible and must facilitate the different levels of language to be used and clarifications to be made by the interviewer.

The relevance of one on one interviews is to offer the researcher an opportunity to interpret nonverbal cues through observation of body language, facial expression, and eye contact and thus may be seen to enhance the interviewer's understanding of what is being said (Meho 2006). Adding, that it permits the researcher to probe and explore hidden meanings and understanding of the subject in question.

For the present study, the interview schedule was set out to aid the study during the interview with the selected IIUM students on a few issues regarding COVID-19 miss information. The respondents were assured of the protection of their responses and the issue of confidentiality was also addressed before the commencement of the interviews. Digital recorders were used for the proper capturing of the responses of the respondents.

Data from the interviews were transcribed verbatim for proper analysis of the responses. Thereafter, the transcripts were given to the interviewees to check if what they said is what was transcribed and that they are happy for it to remain unchanged. This process helps in ensuring the validity of the data and interpretations made by the interviewer. Lathlean (2006) suggests that analysis of qualitative data needs to be rigorous and systematic and how it is carried out will always depend on the particular chosen approach. Adding, that the process of analyzing qualitative data is not linear and is influenced by the aims of the research and the methodological underpimlings of the study.

\section{Data Analysis}

To enable data processing and organization of the interview according to its ideal meaning, recoding of diverse items of the study was done. In this phase, several content variables were used, establishing common categories through an inductive process. Codes were extracted from the verbatim transcripts and thereafter themes emerged from the codes to constitute the findings of the study. the analysis of the themes, therefore, followed while highlighting the meaning of the relevant codes that were generated from the data.

\section{FINDINGS AND DISCUSSION}




\section{Miss information/Fake News Strategies}

Table 1 below summarizes the themes that represent the strategies that were employed by IIUM students in managing COVID-19 miss information and fake news. The themes are reputation and social media content management. The themes are further explained in detail using the codes that were generated from the interview data.

Table 1: Strategies employed by students in managing COVID-19 Fake News/miss information

\begin{tabular}{ccc}
\hline Research Question & Codes & Themes \\
\hline $\begin{array}{c}\text { What are the strategies employed by } \\
\text { students in managing fake news during } \\
\text { the outbreak of COVID-19? }\end{array}$ & Student's image, Branding, & $\begin{array}{c}\text { Student's } \\
\text { reputation }\end{array}$ \\
& $\begin{array}{c}\text { Social Media, Sending verified } \\
\text { information }\end{array}$ & $\begin{array}{c}\text { Social } \\
\text { Media } \\
\text { Content } \\
\text { Management }\end{array}$ \\
\hline
\end{tabular}

\section{Student's Reputation}

Reputation is a major issue revealed by students during the interviews saying that they regard their reputation with high regard. The theme reveals the importance of one's reputation to stay intact even in crises like the current one where students are facing misinformation, particularly from social media. The codes under the theme reputation include student's image and their branding. Student's image and reputation go hand in hand. It is trying to manage the student's perceived image. Reputation becomes a strategy in fighting miss information in a way that, once students find such miss information in their social platforms, they cater so much to their reputation and image, and brand in a way that they do not want to associate themselves with the issues relating to fake news and miss information because they are upright people who treasure what comes out of their mouths.

Reputation management is the attempt to shape some one's perception by influencing how online information is disseminated, in other words, before they send out any miss information, they would first think about their reputation among other students and how they will look at him after knowing that what they sent out was information that misled them in one way or the other. The initial phase in reputation management is observing references to the individual or business, but particularly through social media. 
In addition, the best way to deal with reputation is by taking steps to advance someone's thoughts. Issuing statements through the different social platforms, declarations, and effectively captivating other people's minds through the posts made by an individual. Elaborating on this issue, one of the interviewers said;

"Whenever I encounter misinformation, I always think about my fellow students and how they might have taken this kind of information, therefore, it becomes very hard for me to even think about resending out such kind of information again especially through social media where the issues of fake news are rampant. It is true as a person, I have to do that part yes, because, people mustn't get negative thoughts of you which in return distorts your reputation as a person especially when it comes to social media and relating with the public" (AHZ's communication, January 25, 2021).

In a world that is fully connected, communication impacts the way people perceive and think of you because we all have different thoughts, brand identity, and many more. Additionally, in an era of empowered people, it also includes individuals sharing useful thoughts and content on social media through their accounts. It plays a massive role in improving their public perception among fellow students. This is because individual public relations are generally associated with communication activities designed to preserve their image and relationship with fellow students. therefore, it brings close the issue of individual branding which is likely to be affected once one is engaged in sending information that may appear as misleading to the public.

Some students who participated in this study also revealed the importance of their brand identity. Oftentimes, it is the way how people perceive you and your image and reputation. If an individual can positively promote their branding, they will have great results and promote a great relationship between them and other fellow students. one of them said:

"I always make sure that my image and brand are taken care of whenever I encounter fake news. This is done by way of making sure that my fellow student never receives anything related to fake news from any of my social media platforms because these platforms are my brands and they bear my name therefore, they are my brand and whatever is published on to them, has to be very authentic and relevant to my fellow students" (SM-M Personal communication January 25, 2021). 
From the responses above we can confirm that reputation is a very factor in fighting misinformation relating to COVID-19. Sustaining a sound reputation can act as a buffer to encounter attacks such as fake news because once one is aware of how relevant their reputation is, chances are that they will desist from even thinking about disseminating miss leading information especially on social media. Also, by maintaining a proper image of a person, they can sustain themselves regardless of the false news that comes their way moreover from unknown sources. The participants note that, social media is growing in popularity among many people and that in many cases it acts as the main source that connects people even in dire situations like the current pandemic. These findings correlate with those of Yu and Singh (2002) who found out that, every individual attempts to improve their online presence in an attempt to gain trustworthiness among other fellow students and followers who constantly interact with them daily on social media and other platforms. Therefore, once they are aware of how important their reputation is, the students will be able to fight any misleading information that comes their way by not letting such information distort their images and reputation. By doing that, it indicates that they know what fake news is and miss information and therefore they try to manage it by putting their reputation first before thinking about sending out miss leading information on their platforms.

\section{Social Media Content Management}

Content management is another important theme that was generated from the data as one of the fake news management strategies that students employed to counter misleading information relating to covid-19. The codes generated under this theme include; Social Media, Sending verified information through the different platforms. These are further explained below:

The first code here related to quelling COVID-19 fake news using social media as a strategy. The respondents claim, that one of the vehicles they used in managing fake news among them during the pandemic was through their various social media platforms. These platforms included Facebook, Twitter, Instagram, Telegram, WhatsApp, and others. The participants argue that, when they get any miss information and want to counter it by way of alerting other students, the first option as a communication vehicle to use is social media such Facebook, telegram through the university students group that has thousands of students and where the majority of the news regarding student's welfare and alerts are communicated via in addition to other social platforms 
such as student's WhatsApp groups and personal Twitter accounts because they are quick in disseminating such information virally and in a short period. IMSS said;

"We cannot run away from the fact that social media is an integral part of the current communication domain unlike before where we used depending on the television, radio stations and newspapers. Adding...... we use the opportunity of the presence of the new media platforms to communicate such true information whenever I receive such misleading content regarding the pandemic. I always regard it as the main platform where quick information can be passed through. I have also seen several students pass verified and important information through the official student's telegram group encountering some misinformation that was circulating regarding a positive case at Mahallah Ali, I got to know about it like that and also decided to pass it over to my fellow students in another group. So I always check my information that I send especially through social media" (HRA's statement, 25/01/2021).

Some also added that;

"I just post the right information to my WhatsApp status and it is reacted on by many students because social media platforms are very fast and immediate in conveying such information to a larger audience. In addition, for social media, you can choose how to respond to particular news, you have an option whether you want to do it correctly or you want to misuse your social media platform (SM-M's communiqué, 25/01/2021).

From the responses above, it can be said that the respondents used social media as a response strategy to quell fake news among students because of its effectiveness in conveying information through the different platforms. The responses are consistent with the findings of Haber (2017) who found out that, users should always monitor social media platforms and choose the right one in delivering the relevant information for their messages to reach a wider audience. This helps them in being prepared at all times should the fake news rumors escalate either through their platforms or through proxy ones. Therefore, given the present COVID-19 pandemic in the whole world, students inside and outside the university need to stay alert on the kind of news that they consume from social media especially concerning their parent university and the world at large. This will in a long run help them to extinguish verified and misinformation on the internet and in 
the end, they will find a way of only taking what is relevant from social media and leave out the irrelevant information regarding COVID-19 misinformation.

The second code under social media content management is, that students only send out or publish verified information on their different social media concerning news related to COVID-19. This is another response strategy to counter the COVID-19 misinformation among students. On the above strategy, Farte and Obada (2018) exclaim, that among the different strategies that neutralize the circulation of disinformation is the circulation of accurate information to counter the fake information among people using the different trusted media outlets. The scholars agree, that sending out trusted information is very fundamental in suppressing misinformation because they are verified and have a source on top of always being detailed with the entire process of how the subject matter occurred and how it got to that point especially if the information was obtained through the right channels.

On the above matter, ABK (personal statement, 25/01/2021) argues that he has on many occasions published verifiable information to suppress misleading information clarifying all the rumors regarding COVID-19 that were circulating among students but mostly on the different social media platforms. This information most of them say that they got it from the right and verifiable channels at the university to make sure that they are right in what they were sending out. In addition, there were some online platforms where the participants all agreed to have been the source of most of their correct information that they used to encounter misinformation relating to COVID-19. This strategy is supported by previous literature of Wynne (2016) who found out, that since fake news is one of the biggest challenges faced by social media users, solid measures are required to quell the problem even if it means using the same platforms that they use for misinforming their followers and the public at large. Some of those platforms include websites and other media platforms that are used because they attract traffic such as social media platforms.

Accordingly, such media platforms are sometimes used to distribute official responses to the crisis at hand like the present pandemic but also because information got from official platforms for professional bodies like the university is easily believable because they operate under certain values and have ethics that they work with. Therefore, it is very hard to find misleading information on such platforms. 
Consequently, the students at IIUM also applied the same technique, by publishing correct information countering the fake news and or any COVID-19 misinformation through the different social platforms both the ones that they manage and those that belong to other students who think alike in terms of correcting the wrongs in the society. The respondents also affirmed that announcements through online platforms are a very vital strategy in countering fake news on COVID-19 among students because the students constantly check for important information from those sites regarding their studies. Therefore, with such important information uploaded there, there are high chances of them seeing the announcements very quickly and believe them instantly without doubt unlike social media which can easily be hacked in and manipulated at the same time, this also helps in quelling any miss information published in the social media (AHZ's communication, January 25, 2021).

\section{Problems faced by students in managing COVID-19 Fake News/Miss information}

Table 2 represents the dominant themes regarding the problems that students faced as a result of managing fake news during the pandemic. The themes include; Regulation and prevention. These are also explained further using the codes extracted from the interview verbatim as data for the study.

Table 2: Problems faced by students in managing Fake News during the pandemic, and their solutions

\section{$\begin{array}{lll}\text { Research Question } & \text { Codes } & \text { Themes }\end{array}$}

What challenges did students face as a result of managing fake news and misinformation regarding COVID-19 at campus?

How did the students overcome the challenges they faced in managing fake news and misinformation at Campus during the outbreak of COVID-19?
Fake News, Monitoring the many fake news, lack of prescribed strategy, Gatekeepers, lack of knowledge on what is fake news

Media communication, Guidelines, Combating Negative Situations, Corporation,
Regulation of students

\section{Prevention}

\section{Regulation of Students}


Regulation is one of the other themes extracted from the data and agreed upon by the respondents in the study as one of the challenges that students face while managing COVID-19 fake news at the campus. The codes under regulation as a theme include; Fake News, Infodemic, Monitoring the many fake news, lack of prescribed strategy, Gatekeepers, lack of knowledge on what is fake and what is not fake news

The first code reveals, that regulating the circulation of fake news is a significant tool in managing the spread of disinformation among students at IIUM however, there are no university regulations regarding the spread of misinformation and therefore, as students, they post whatever they feel comfortable for them. Several scholars on fake news and misinformation believe that fake news is a very dangerous aspect that can cause another pandemic on its own. This finding concurs with that of Allcott and Gentzkow (2017) who in their study found out, that fake news can affect media users because of the deliberate and unverifiable information that may mislead people into a wrong direction because of the misinformation on a particular subject like the pandemic. Therefore, the respondents also attributed it to one that spreads like a virus itself. On that note, one of the participants (ABK) said;

"Fake news itself is an infodemic. It is a kind of communication virus and pandemic on its own. Malaysia's minister of health Dato Hisham, in one of his press conferences on the updates of COVID-19 referred to misinformation as a dangerous virus were by taking care of COVID-19 is easier than taking care of its misinformation" (ABK personal statement, 25/01/2021).

From the above admittance about the spread of fake news, it can be concluded, that it is not easy to manage fake news especially when there are thousands of people who help in spreading false news regarding COVID-19 because of the freedoms of expression that is inalienable to everyone. In fact, as a public, we are living in an era of citizen journalism, where every individual with a digital gadget can act as a journalist, provided that they can point their gadget camera or decoder in front of a newsmaker and start recording thereby reporting the way they see fit. This is in contradiction with the journalistic ethics that demand publishing verified information on any media platform.

The respondent's claims of the problematic ways of dealing with miss information are supported by numerous posts from Centre for Disease Control (CDC) and WHO websites that have so far 
received numerous engagements, shares, and comments on social media where a number of them are fake news websites that publish COVID-19 misinformation and have so far received millions of engagements in form of likes, shares and comments (WHO, 2020).

Fake news can be fought in very many different ways especially in institutes of higher learning like IIUM. Several studies have identified ways through which fake news can be fought. David et al. (2018) climaxed that, fake news can lead to many disorders in society and therefore should be managed with covert strategies that aim at quelling the practice from the society for good.

According to one of the Informants (AHZ, personal statement, 25/05/2021), as students, they have encountered many rumors during the pandemic, and that they have been having problems in dealing with fake news about COVID-19 that circulates amongst fellow students. it should be noted that COVID-19 rumors amongst IIUM students started when the university decided to take a holiday for ten days at the onset of the pandemic even while other universities remained open. During the closure, the rumors of the alleged COVID-19 cases at IIUM started, and being an international university with thousands of students from different countries and the fact that the semester was just starting, there were many fears and panic as a result of those fake news rumors. All these factors contributed to the hype of the rumor to continue to the students outside the university as the entire public started panicking over the same. One of them said;

"When I saw the rumor of the first positive case at the campus, I panicked and the fact that the university had decided to take a break and then allowed local students to go home but also international students wanted to go home and those who could go used that chance and went. The university however tried to clarify the matter by putting numerous statements on their social media platforms as well as the website but all was not yet well because the rumors were already circulating on Twitter, Instagram, Facebook, saying all sorts of things as there is a student who had already contracted the virus and that 'IIUM is now under lockdown', and that 'Police are already on the campus'. One student wrote and said 'I have seen an ambulance taking students from mahallah Aminah'. All this came out as a result of that rumor. But when the university clarified, I took the positive out of it because it was the right thing to do" "SM-M personal statement, 25/01/2021".

It can be concluded that people create their assumptions about what happens in situations like the current pandemic. They will post anything that they feel is right for them not minding about its 
effects on the community. In addition, everyone needs to be responsible to stop spreading false news during a pandemic like this one. Fake news is a serious issue that students at IIUM are facing right now because it moves fast without knowing whether the news is reliable or not. This revelation is supported by World Health Organization (2020) when its Director-General, Tedros Adhanom Ghebreyesus said, that misleading information is seen as a serious issue for public health because people require advice or guidance to take action for them to protect themselves and others around them and help diminish the impact of the disease.

The third code concerns the monitoring of fake news which was also another problem that IIUM students faced while dealing with COVID-19 misinformation. According to Informant ABK (personal statement, 25/01/2021), many students face this issue of monitoring the different types of fake news that circulate particularly on social media, and that because everyone takes care of their social platforms, it sometimes becomes hard to keep a tab on the different misinformation that is being circulated in WhatsApp or other social groups if one is not aware of it. Therefore, it's not easy to monitor each student but everyone on their own. This finding is in line with the study by Haber (2017), who concluded, that public relations practitioners should act quickly by monitoring social media, choose the right way to the platform, develop messages and prepare statements to counter any misinformation with the actual truth. Therefore, the lack of a proper strategy in monitoring student's social platforms also hinders the efforts of quelling the spread of fake news because it's not easy to spot who is spreading the misleading information. The source is most cases is not easy to spot.

The other code concerns gatekeeping. The participants agreed that it is very important to control how information is being spread. However, in this case, it has been very hard for them to keep and or manage how information flows among fellow students and the fact that everyone is responsible for their gadgets and social platforms. This became problematic especially when it comes to what students are supposed to post or publish on their social pages and what they are not supposed to publish. It becomes very hard to regulate them on what to do with their platforms. Also, being a gatekeeper allows you to manage the perception of the stakeholders as well as the perception of the public. Using crisis communication strategies can enhance the relationship between the users and the followers. 
All the participants acknowledged that one of the problems they faced while encountering fake news about COVID-19 was for them to assume the role of gatekeeping for any news or information that they intended to circulate to their followers and fellow students after receiving it from the different sources. This finding is very important because it acts as a barrier to any fake news that would have circulated among the students because are aware of the message and how to counter any contrary information. Gatekeeping in news organizations is usually a job designated for news editors who are mandated to screen every story that they intend to publish, in search of misleading statements in a particular story. The same case happens here, whereby the students in the bid to try and look for the relevant misleading information as well as contextual information to make sure that the information they send to their friends is accurate and has a source and is very well verified.

According to Informant (SM-M), he said that the management of the university has to put out measures to make sure that students consume verifiable information and try and refrain them from circulating wrong and misleading information. Also, social media is very close to students and because they use it every day, thus, social media is the right medium for them to communicate with their fellow students and yet it accommodates a lot of misleading information relating to the COVID-19 pandemic. the informant said;

"When I am sharing any information relating to the pandemic on WhatsApp, it is like iam sharing it for the entire student's community because, in one way or the other, they will receive it, and if it turns out to be false, that means iam countable for that particular information because it went out through one of my platforms" (SM-M's statement, 25/01/2021).

The last code concerns student's inability to distinguish between what is fake and not fake news. This stood out from the interviews as one of many problems that they faced because it is hard to fight such a deadly disease if you do not know how the disease is contracted. Therefore, not knowing what misinforming is a huge problem among the students and still is because much of the information we receive nowadays in our social media platforms regarding COVID-19 is in many cases not verifiable but if someone lands on it, they just send it to other social groups that they have in their contacts. This has caused more spread of the vice and hence a problem.

\section{Prevention}


The last theme is prevention and the codes under it include; guidelines, combating negative situations, and collaboration and problems in monitoring fake news that circulate. These are further broken down in a detailed subsequent discussion. Preventing fake news from being spread and combating fake news is very crucial in making sure that the individual's reputation is not tarnished. In preventing fake news from not being spread uncontrollably, people need to have well-planned strategies beforehand to help in the management of such crises as and when they occur. This is to ensure that they know how to handle the situation in a good manner. Students at IIUM had some knowledge of preventing some information to be circulated among fellow students but it's not easy to regulate all the students as there are no regulations regarding information flow especially regarding fake news.

Under prevention, media communication and cooperation are some of the strategies that the students employed to combat fake news. This is where they used social media in communicating to fellow students about the situation at hand and countering the false information with the right one. HRA on his (personal statement, 25/01/2021) stated that sometimes he monitored his social media platforms to know whether there is any fake news that relates to COVID-19 that has been sent to him. He said:

In fighting the fake news, as I said to you, I can't prevent anyone from sending out what they want because they are using their platforms. Also, because fake news comes from social media, it becomes hard to trace its origin. Therefore, sometimes it becomes hard but we try to do what is necessary to make sure that we send out only verifiable information related to the pandemic as and whenever we receive it (HRA's statement, 25/01/202).

From the above admittance, we can confirm, that the respondents encountered minor problems while monitoring fake news that circulates in their social media platforms. However, as has been mentioned earlier, they did have their strategies in combating the false news. Other codes here relate to obeying the standard operating procedures related to information circulation and not just send out COVID-19 information because you have received it on social media. Adhering to the guidelines was also very important in this aspect of trying to combat the spread of misinformation relating to COVID-19 among students.

In general, it can be said that the participants have so far tried to manage the issue of fake news that they encounter on their social platforms. They came up with strategies to combat fake news 
or speculation regarding COVID-19 among students. To be more specific, they mostly used social media to combat and prevent fake news from being spread.

\section{CONCLUSION AND RECOMMENDATIONS}

This study was set out to examine the response strategies employed by students at IIUM in managing COVID-19 fake news. Among dominant themes that emerged concerning strategic response include; student's reputation and social media content management. Research questions two and three were answered with themes such as regulation of students and prevention respectively.

Results from the data analyzed indicate, that the students employed their strategies to manage the FOVID-19 fake news amongst them. This was well executed through the many digital media platforms that were used by the students to suppress any rumors that were circulating regarding the alleged COVID-19 cases amongst students. Although the university did not prepare for such a crisis to arise, through the use of effective corporate communication strategies, the students were able to successfully mitigate the circulation of Fake News that was rampant on social media.

Furthermore, the other issue that the current study brought out was that of lack of prescribed punishments either in the student's perspective or the staff themselves in regards to the spread of the fake news is alarming. This is very visible because even if one is caught spreading such, the university seems not to have proper punishments prepared for such culprits. This is seen as a very big gap that needs the attention of the university management for the better management of the future strategies in times of crises. Therefore, the study accordingly recommends, that the university find a solution to either inserts a regulation amongst the student and staff regulations in regards to the spread of false information especially to damage the image of the university and the student community at large.

The findings of the study have acknowledged, that the situational crisis communication theory appropriately guided the study because it lays down very well, how a crisis can be managed and overcome in times of need. However, future studies should try and look at other theories like the crisis management model, butterfly theory of crisis management, psychological first aid model, 
and others, to try and infuse the issue of managing crises especially during emergencies like pandemics.

This study is also limited by the fact that it considered only five respondents. This study considered interviews with purposely selected students who had encountered some fake news regarding COVID-19 respondents. In addition, the spread of COVID-19 was too much and discourages students from gathering to do such kinds of activities as the interview. Further studies should incorporate other representatives that could provide in-depth knowledge on the matter to widen the scope of the findings and responses to get more evidently rich data. 


\section{REFERENCES}

Ahmad, Z. A. (2012). PR and CSR: Malaysian perspectives. Communications, Media and Culture eTheses, University of Stirling.

Allcott, H., \& Gentzkow, M. (2017). Social media and fake news in the 2016 election. Journal of Economic Perspectives, 31(2), 211-236. https://doi.org/10.1257/jep.31.2.211

Ang, M. V. (2020, March 3). "Not sure, don't share" - Here's all the latest covid-19 fake news moh has debunked. Retrieved from https://says.com/my/news/not-sure-don-t-sharehere-s-all-the-latest-covid-19-fake-news-moh-has-debunked

Anney, V. N. (2014). Ensuring the quality of the findings of qualitative research: Looking at trustworthiness criteria. Journal of Emerging Trends in Educational Research and Policy Studies (JETERAPS), 5(2), 272-281.

Berg, B. L. (2009) Qualitative research methods for social Science. Allyn and Bacon, Boston.

Bernama. (2020, February 5). Chinese girl recovers from coronavirus, discharged from: hospital.Retrieved from: https://www.bernama.com/en/general/news.php?id=1811559.

Boo, S. L. (2020). Malaysia's Covid-19 epidemic unpredictable without good data: Expert. Retrieved from: https://codeblue.galencentre.org/2020/04/06/malaysias-covid-19epidemic-unpredictable-without-gooddata-expert/

Borneo Post. (2020, January 25). First coronavirus cases in Malaysia: 3 Chinese nationals confirmed infected, quarantined in Sungai Buloh Hospital. Retrieved from: https://www.theborneopost.com/2020/01/25/first-coronavirus-cases-in-malaysia-3chinese-nationals-confirmed-infected-quarantined-in-sungai-buloh-hospital/

Bryman, A., \& Becker, S. (2012). Qualitative research.

Bryman, A. (2016) Social research $5^{\text {th }}$ edition, 'qualitative data analysis' $p g .569-588$, thematic analysis as the basis for a genetic approach to qualitative data analysis.

Carcary, M. (2009). The research audit trail-enhancing trustworthiness in qualitative inquiry. The Electronic Journal of Business Research Methods, 7(1), 11-24.

Comcowich, W. (2020). How PR Can Respond to the Coronavirus Contagion. Retrieved from: https://www.business2community.com/public-relations/how-pr-can-respond-to-thecoronavirus-contagion- 02285868

Coombs, W. T. (2007). Protecting organization reputations during a crisis: The development and application of Situational Crisis Communication Theory. Corporate Reputation Review, 10(3), 163-176. doi:10.1057/palgrave.crr.1550049

Ewing, M., \& Lembert, C. A. (2019). Listening in: fostering influencer relationships to manage fake news. Public Relations Journal, 12(4), 2-15.

Farte, G. I., \& Obada, D. R. (2018). Reactive Public Relations Strategies for Managing Fake News in the Online Environment. Postmodern Openings, 9(2), 26-44. doi:10.18662/po/16

Grunig, J., \& Hunt, T. (1984). Managing public relations. Fort Worth, Harcourt. 
Haber, M. (2017). The Real Risks of Fake News.

Hasnan, L. (2019, October 3). Are Malaysian teens aware of fake news? Retrieved from https://theaseanpost.com/article/are-malaysian-teens-aware-fake-news

Hu, Z., Yang, Z., Li, Q., \& Zhang, A. (2020). Infodemiological study on Covid-19 epidemic and Covid-19 infodemic. Preprints, 1-32. https://doi.org/10.20944/preprints202002.0380.v3

Hsieh, H. F., \& Shannon, S. E. (2005). Three approaches to qualitative content analysis. Qualitative health research, 15(9), 1277-1288.

Kasirye, F., Radwan, H., \& Kreya, M. (2020). Assessing the 2014 Cadbury controversy through the Theory of Planned Behavior. Advance. Preprint. https://doi.org/10.31124/advance.12012675.v1.

Lathlean, J. (2006). The research process in nursing.

Lazer, D., Baum, M., Benkler, Y., Berinsky, A., Greenhill, K., Menczer, F., Metzger, M., Nyhan, B., Pennycook, G., Rothschild, D., Schudson, M., Sloman, S., Sunstein, C., Thorson, E., Watts, D., \& Zittrain, J. (2018). The science of fake news: Addressing fake news requires multidisciplinary effort. Science, 359(6380), 1-4. https://doi.org/10.1126/science.aao2998

Lincoln, Y. S., \& Guba, E. G. (1985). Naturalistic inquiry. Beverly Hills, CA: Sage.

Lipstichh, M., \& Swerdlow, D. L. (2020). Defining the epidemiology of Covid 19 - studies needed. New England Journal of Medicine 2020.

Malaysian Communications and Multimedia Commission. (2020, January 29). Press release: Four individuals detained for spreading fake news on the novel coronavirus (2019 ncov) outbreak. Retrieved from https://www.mcmc.gov.my/en/media/press- releases/pressrelease-four-individuals-detained-for-sprea

Miles, Huberman, A. M., Huberman, M. A., \& Huberman, M. (1994). Qualitative data analysis: An expanded sourcebook. Sage.

Ministry of Health. (2020). COVID-19 Update. Retrieved from: http:/www.moh.gov.my/index.php/pages/view/2019-ncov-wuhan.

Ministry of Health Malaysia. (2020). Press statement: updates on the coronavirus disease 2019 (Covid-19) situation in Malaysia. Retrieved from: https://kpkesihatan.com/2020/04/04/kenyataan-akhbar-kpk-4-april-2020- situasi-semasajangkitan-penyakit-coronavirus-2019-covid-19-di-malaysia/

Ministry of Health Malaysia. (2020). Press statement: updates on the coronavirus disease 2019 (Covid-19) Situation in Malaysia. Retrieved from: https://kpkesihatan.com/2020/03/17/kenyataan-akhbar-ybmk-17-mac-2020- situasisemasa-jangkitan-penyakit-coronavirus-2019-covid-19-di-malaysia/

Nelson, J. L., \& Taneja, H. (2018). The small, disloyal fake news audience: The role of audience availability in fake news consumption. Sage Publication, 00(0), 1-18. https://doi.org/10.1177/1461444818758715 
New Straits Times. (2020, January 25). 3 coronavirus cases confirmed in Johor Baru. Retrieved from:https://www.nst.com.my/news/nation/2020/01/559563/breaking-3-coronaviruscases-confirmed-johor-baru.

Perlow, J. (2020, March 3). Coronavirus misinformation spreading fast: Fake news on covid19 shared far more than cdc, who reports. Retrieved from https://www.zdnet.com/article/coronavirus-misinformation-is-increasing-newsguardfinds/

Pulido, C. M., Villarejo-Carballido, B., Redondo-Sama, G., \& Gómez, A. (2020). Covid-19 infodemic: More retweets for science based information on coronavirus than for false information. International Sociology, 35(4), 377-392. https://doi.org/10.1177/0268580920914755

Ragavan, S. (2020). How should brands handle their comms during the coronavirus crisis? Retrieved from: https:/www.prweek.com/article/1672719/brands-handle-comms-duringcoronavirus-crisis

Rusly, R. (2020, February 2). Fake news on novel coronavirus (2019-nCoV). Retrieved from https://www.iium.edu.my/news/fake-news-on-novel-coronavirus-2019-ncov

Senger, H. (2005). The 36 stratagems for business: achieve your objectives through hidden and unconventional strategies and tactics. Cyan Communications.

Shu, K., Sliva, A., Wang, S., Tang, J., \& Liu, H. (2017). Fake news detection on social media: A data mining perspective. ACM SIGKDD explorations newsletter, 19(1), 22-36.

Singhal, T. (2020). A review of coronavirus disease-2019 (COVID-19). Indian J Pediatr 2020; 87(4):281-6.

Smith, D. R. (2002). Strategic planning for public relations. London: Taylor \& Francis e-Library.

Standage, T. (2017, July 2017). The true history of fake news. Retrieved from https://www.1843magazine.com/technology/rewind/the-true-history-of-fake-news

Surico, P., \& Galeotti, A. (2020). The Economics of a Pandemic: the case of Covid-19. Retrieved from: https://icsb.org/wp-content/uploads/2020/03/LBS_Covid19_final.pdf.pdf.pdf.pdf1.pdf.pdf

Thiessen, A., \& Ingenhoff, D. (2011). Safeguarding reputation through strategic, integrated and situational crisis communication management. Corporate Communications: An International Journal, 16(1), 8-26. doi:10.1108/13563281111100944

Tod A. (2006) Interviewing. In: Gerish K, Lazey A, eds. The research process in nursing. Blackwell publishing.

What is Covid-19? (2020, February 27). Retrieved from: https:/www.theguardian.com/world/2020/feb/27/what-is-covid-19

Wong, Q. (2019, June 5). Fake news is thriving thanks to social media users, study finds. Retrieved from https://www.cnet.com/news/fake-news-more-likely-to-spread-on socialmedia-study-finds/ 
World Health Organization. (2013). Global action plan for the prevention and control of noncommunicable diseases 2013-2020. World Health Organization.

World Health Organization. (2020, April 1). Report of the Who-China Joint Mission on Coronavirus Disease 2019 (COVID19). Retrieved from: https://www.who.int/docs/default-source/coronaviruse//who-china-joint-missiononcovid-19-final-report.

World Health Organization, (2020, April 4). Coronavirus Disease 2019 (COVID-19): situation report, 75. Retrieved from:

https://www.who.int/docs/default-source//coronaviruse/situation-reports/20200404sitrep-75-covid19.pdf?sfvrsn=99251b2b_2.

World Health Organization, (2020, April 15). Coronavirus disease 2019 (Covid-19) situation report-86. Retrieved from:https://www.who.int//docs/defaultsource/coronaviruse/situation-reports/20200415-sitrep-86-covid 19.pdf?sfvrsn=c615ea20_6

Wynne, R. (2016). Public relations in a post-factual fake news world. Retrieved from: https://www.forbes.com/sites/robertwynne/2016/11/14/public-relations-in-a-post-factualworld/\#3c6692263cb3

Yatid, M. M. (2019). Truth tampering through social media: Malaysia's approach in fighting disinformation \& misinformation. The Indonesian Journal of Southeast Asian Studies, 2(2), 203-230. 